UDC 331

\title{
EXPLORING THE FACTORS AFFECTING THE IT MATURITY OF IT OUTSOURCING CLIENT ORGANIZATIONS
}

\author{
Donghwan Cho \\ Department of Business Administration, Gyeongnam National University of Science and \\ Technology (GnTech), Gyeongnam, South Korea \\ E-mail: dhcho@gntech.ac.kr
}

\begin{abstract}
The rapid development of information technology makes it difficult for many modern organizations and companies to effectively manage information technology, and as a result, IT outsourcing has been continuously expanded and developed. Furthermore, the recent virus pandemic has put many companies in a situation where even the survival of companies cannot be guaranteed unless they effectively utilize and outsource information technology. However, in many cases, actual outsourcing performance is not provided as expected, and the difference in performance varies greatly depending on the company. Therefore, this study attempted to identify the factors that influence the maturity of information technology of outsourcing clients in order to reduce these differences in performance and improve outsourcing performance. To this end, through literature research, the strategic performance of outsourcing, the maturity of information technology, and the role of information technology were investigated, and a series of research propositions established based on these studies. The results of this study can be used to solve the problem of insufficient outsourcing performance experienced by many organizations and companies. Furthermore, the results of this study are expected to be used to improve organizational productivity by improving outsourcing performance.
\end{abstract}

\section{KEY WORDS}

IT outsourcing, outsourcing strategic performance, IT role, IT maturity.

The trend of outsourcing information system activities is expected to increase steadily. For this reason, cost reduction, which has been pointed out as the traditional rationality of outsourcing in the past, improves the performance of information technology through economies of scale and specialization of external suppliers, and increasing the efficiency of information technology resources was pointed out (Lacity \& Willcocks, 2017). However, when looking at the recently emerged form of information technology outsourcing, these factors only explain some of the reasons for outsourcing information technology. Looking at the recent outsourcing of innovative companies, information technology outsourcing is viewed not from tactical intentions, but from strategic intentions, and information technology is outsourced to maximize the effect on business (Bapna et al., 2010; Gregory et al., 2009). They are pursuing a new role in information technology outsourcing, and are seeking a new route of relationship between outsourcing customers and external suppliers.

As the scale and role of information technology outsourcing is increasing, it can be said that the successful execution of outsourcing is very important (Kudaravalli et al., 2017). However, a large number of information technology outsourcing has not produced the expected cost reduction or other effects. The reasons are as follows. First, managers are not able to carefully select which information technology activities to outsource. Second, there is an incorrect relationship between outsourcing external suppliers and customer companies. The relationship between them is not just contracted, but it is desirable to move toward a partnership through strategic alliances. Third, there is a problem of incorrect contracts with external outsourcing providers. The competitive environment surrounding companies is changing rapidly, but contracts with external suppliers of outsourcing did not sufficiently consider the countermeasures for the changing competitive environment.

When making decisions about outsourcing information technology, some companies do 
not consider or ignore the company's strategy or the role of information technology, and think only what can be achieved through outsourcing, so that there is a gap between the business strategy and the role of information technology and the outsourcing strategy. There is also a misalignment. Due to this inconsistency, outsourcing of information technology may fail or result in failure to achieve the expected effect. Therefore, there is a need for a study on the successful introduction of outsourcing considering the role of information technology in outsourcing organizations or information technology maturity.

This study attempts to explore the factors that influence the maturity of information technology of outsourcing customers in order to improve IT outsourcing performance of outsourcing customers. More specifically, based on prior research, this study attempts to investigate how the maturity of information technology varies and is affected by the characteristics of the organization and the role of information technology within the organization.

\section{LITERATURE REVIEW}

\section{IT Outsourcing Decision Making}

Outsourcing strategy is a business approach to outsourcing as a cross-organizational, long-term strategy designed to achieve a sustainable competitive advantage (Jennings, 2002). Most of these outsourcing strategies are aimed at improving efficiency and achieving innovation (Wu et al., 2009). First of all, an outsourcing strategy with the main purpose of improving efficiency has the result of reducing costs and improving productivity by entrusting routine and non-core activities to external specialized organizations.

There is a study on the concept of outsourcing in a new approach that is different from the traditional concept of outsourcing. Cross (1995) argued for the efficiency and effectiveness of selective outsourcing in the case of British Petroleum. In order to overcome the disadvantages of high rates and inflexible services, this was promoted under a strategy in which each service was provided from several external providers, and these services were provided by a single external provider. Through outsourcing, internal IT department members have demonstrated benefits such as improving business processes, reducing costs, and being able to focus on the creation of new business opportunities.

Lacity et al. (1995) pointed out the problem of the strategy versus the commodity approach when making outsourcing decisions, and argued that the goal of maximizing flexibility and coordination by maximizing competition between external suppliers is necessary, and maximizing such flexibility and coordination. For this, it has been shown that selective outsourcing is appropriate.

Lacity and Willcocks (1998) suggested the following five ways to successfully outsource information technology. First, selective outsourcing is performed rather than total outsourcing or total outsourcing. Second, decision-making on outsourcing is made with executives and heads of information systems rather than stakeholders. Third, rather than comparing the performance based on the current required cost and the required cost suggested by an external supplier, the performance is compared by competing with the internal information system department and external suppliers. Fourth, short-term contracts are concluded rather than long-term contracts. Fifth, the service of the external provider is classified in detail, and a contract is concluded with the external provider under the condition of paying fees only when the service is performed.

Benbasat et al. (1980) used Nolan's staged hypothesis model and other independent studies to classify information technology maturity into two groups: "more mature" and "less mature." These are less mature information systems organizations. Compared to mature organizations, it was considered to be superior in nine evaluation criteria such as hardware expenditure, experience of using information systems, status of information system department, user interest, role of high-level manager, and information system budget establishment process.

McFarlan et al. (1983) suggested a four-stage theory explaining the process of internalizing new information system related technologies within the organization by linking 
the four-stage hypothesis model of Nolan (1974) with the organizational change theory of Shine (1961). The four stages of this theory consist of the stage of technology recognition and investment, the stage of acquisition and application of the technology, the stage of rationalization and management control, and the stage of maturation and technology diffusion.

\section{IT Outsourcing Strategic Performance}

Companies use a number of performance indicators to measure the performance of their outsourcing strategies. First, innovation, financial performance, and stakeholder performance can be measured (Gilley and Rasheed, 2000), responsiveness or flexibility can be measured (Handley and Benton, 2009), and the time it takes for a product to market, product functionality., Time specificity, etc. are also measured (Bengtsson et al., 2009). In other words, in order to measure the outcome of outsourcing, it is necessary to measure the cost reduction dimension and the overall strategic value dimension at the same time. Many factors have to be reviewed down to the strategy (Zhou and Li, 2010).

In the past, most of the IT outsourcing was introduced for the purpose of cost reduction, and corporate resources were concentrated on core competencies and non-core areas were expected to result in productivity improvement (Kang et al., 2012). However, today's IT outsourcing often results from rapid changes in the business environment, not from the cost aspect. In other words, in order for companies to continuously adapt to rapidly changing business environments and technologies, existing information systems must be steadily maintained/repaired or replaced, and the time to replace such information systems is gradually shortening, so it is essential to increase IT flexibility. However, it is not enough for companies to keep the IT environment up-to-date while concentrating the organization's resources on core competencies, especially in the technology-intensive market (David et al., 2009). Therefore, today, more and more companies are adopting outsourcing for the purpose of improving IT flexibility rather than simply reducing costs.

Bunmi et al. (2004) stated that selective outsourcing of some functions in a company can facilitate change, which greatly improves flexibility and greatly improves the quality of service. In particular, in a technology-intensive market, it is easier to secure strategic flexibility if you can use IT outsourcing to obtain technical help when continuously developing new products for the survival of the company, or if you can maintain a close relationship with IT technology providers in the offshore market. It can be done (David et al., 2009).

More IT flexibility is required in technology-intensive markets, and there are two fundamental problems that can be overcome through IT outsourcing (Williamson, 1991). The first problem is that there is a risk of obsolescence of knowledge and facility capabilities in a market where rapid technological advancement and fierce competition occur (Swan and Allred, 2003). When a lot of resources cannot be invested in information system development and maintenance/repair, companies can use IT outsourcing to reduce investment costs while improving flexibility and productivity. The second problem is that amid extreme change, companies face a variety of costs and threats (Appleyard, 2003). Even in such cases, companies can respond flexibly by reducing the difficulty in coordination and inconsistency between their current technology and the new environment through IT outsourcing, and at the same time benefit from reducing the cost of switching to technology and suppliers (Stump and Heide, 1996).

\section{IT Maturity}

The concept of IT Maturity was first mentioned in the work of Churchill et al. (1969), and Nolan (1973) developed the constituent concept using the Stage hypothesis model. According to this model, information system-related costs follow a "S-curve" path over time. This path is described in four stages: initialization, proliferation, control, and maturity. Later, Nolan changed the Stage hypothesis model to consist of six stages. These six steps are described as initialization, proliferation, control, integration, data control, and maturity (initiation, contagion, control, integration, data administration, maturity).

Benbasat et al. (1980) used Nolan's staged hypothesis model and other independent 
studies to classify information technology maturity into two groups: "more mature" and "less mature." These are less mature information systems organizations. Compared to mature organizations, it was considered to be superior in nine evaluation criteria such as hardware expenditure, experience of using information systems, status of information system department, user interest, role of high-level manager, and information system budget establishment process.

McFarlan et al. (1983) suggested a four-stage theory explaining the process of internalizing new information system related technologies within the organization by linking the four-stage hypothesis model of Nolan (1974) with the organizational change theory of Shine (1961). The four stages of this theory consist of the stage of technology recognition and investment, the stage of acquisition and application of the technology, the stage of rationalization and management control, and the stage of maturation and technology diffusion.

Information technology maturity was re-conceptualized in the form of a technology assimilation model. This model describes the overall process of information technology diffusion and explains how the information technology management strategy evolves as the organization moves toward information technology maturity. In this model, the process of dissemination of information technology is divided into four phases: technology identification and investment process, learning and application process, rationalization and management control process, and extensive technology transfer process. This study proposes: First, the goal of assimilating technology change over four stages, second, that different management methods are needed depending on the stage of technology adoption, and third, when responsibilities between experts, users, and management change the process of growth (learning) evolves.

Karimi et al. (1996) viewed the maturity of information technology as an evolutionary degree in terms of planning, organizing, controlling, and integrating the functions of an organization's information system. In their research, information technology maturity is measured by all 20 items, and a high level of information technology maturity means that the above four aspects of information technology activity have a very high degree of formalization. This high formalization of information technology activities implies that the information system department has evolved from a data processing oriented to a strategic information system oriented.

\section{THEORETICAL FOUNDATION AND PROPOSITION DEVELOPMENT}

\section{Organizational Characteristics}

Cheon (1992) conducted a field study on the effects of information system-related factors and organization-related factors on information technology outsourcing and factors related to success in information technology outsourcing. As a result of the empirical analysis, five factors affect outsourcing, including information quality, information system quality, information system cost effectiveness, financial performance, and the organizational role of information technology. It turned out to be related to success.

Grover and Teng (1993) believe that the strategic analysis of decision-making for outsourcing, contrary to the conventional perspective, is determined to outsourcing through a more detailed process. According to this model, outsourcing is determined by the maturity of the information system, the ripple effect of introducing outsourcing, and the ability of information technology compared to competitors. This shows that the reason for the outsourcing decision in the past is changing from a simple cost perspective to a decision that depends on the company's needs and environment (see [Figure 2-2]).

Grover et al. (1994) describe that the size of an organization is an important factor influencing outsourcing decisions. Because external suppliers can achieve economies of scale by mass production and economies of scope by labor-specific efficiencies, they can achieve lower average costs compared to internal information technology departments. Small-sized companies can expect significant cost savings through the economies of scale of external providers by outsourcing. On the other hand, large-scale companies can achieve 
cost savings through in-sourcing as they can achieve economies of scale comparable to those of external suppliers. Therefore, smaller companies make relatively more outsourcing decisions than larger ones.

\section{IT role in the organization}

Information systems applications in organizations have come to support decision making and provide tools for competition from automating clerical processes over time. As a result, there is a growing awareness that information technology plays a more important role than ever in corporate strategy.

Johnston and Carrico (1988) argued that information technology has three different roles in relation to organizational strategy. The first is a traditional role that is not related to the organization's strategy, assisting the operation of the company and revitalizing decision support and administrative functions. Second, as a developmental role, information technology in this role actively supports organizational strategy, but is not an essential part of the strategy formation process. Third, as an essential role, the Chief Information Officer (CIO) and executives work together to make information technology an integral part of corporate strategy, making it a tool to change competition patterns in the industry. This role enables information technology to improve productivity, enable new management and organizational approaches, create new products and new services, transform supplier-consumer relationships, and ultimately establish new performance standards in the industry. It is used as a strategic weapon to gain competitive advantage by making it.

In the study of Teng et al. (1995), it was found that the strategic roles of various information technologies were significantly related to outsourcing decisions. In terms of the number of organizations making outsourcing decisions, information technology is most often the traditional role, followed by the developmental role, and then the essential role. The meaning of this analysis result is that when the information system function is strategic or essential to the business process, the rate of outsourcing decreases. Conversely, when the information system function is considered to be non-strategic or not essential to the business process, the rate of outsourcing is lower. It is to increase. Therefore, if many functions are regarded as an essential case in the process of being left to external providers, it means that information systems are actually less outsourced. These argument leads to the following propositions:

- Proposition 1: Organizational characteristics such as organizational strategies and organizational size affects IT maturity.

- Proposition 2: IT role in the organization affects IT maturity.

- Proposition 2a: Traditional IT role is related with the low level of IT maturity.

- Proposition $2 \mathrm{~b}$ : Developmental IT role is related with the moderate level of IT maturity.

- Proposition 2c: Essential IT role is related with the high level of IT maturity.

\section{CONCLUSION}

Information technology, which is rapidly developing, makes it difficult for many companies and organizations to effectively manage information technology, and outsourcing will expand further in the future in terms of size and form. Therefore, research to improve outsourcing performance, which is still not meeting expectations, is theoretically and practically very necessary. In this study, we focused on the IT maturity of outsourcing customers to improve the performance of IT outsourcing, which is continuously increasing, and tried to reveal what factors affect IT maturity. To this end, extensive literature research on the strategic performance and IT maturity of IT outsourcing was conducted, and based on this, the propositions on the organizational characteristics such as the strategy and size of the organization, IT maturity, and the role of IT and IT maturity within the organization were presented. Was set up. In particular, the role of IT in an organization has a variety of roles ranging from traditional to core roles, and it is inferred that the level of IT maturity will vary according to these roles. 
IT outsourcing has developed or evolved through several stages, and nowadays, which is experiencing a virus pandemic, it is difficult to ensure the survival of business without effective use of information technology. Nevertheless, it is true that the use of information technology through outsourcing differs greatly depending on the capabilities of an organization or IT maturity. In addition, IT outsourcing has not been able to provide the actual results as it was promised, so the gap between theory and reality is still very large. If the research results in this study are properly utilized, this gap will be narrowed a little, and it is expected that the clues to solving the problem of improving outsourcing productivity that modern organizations are experiencing will be found.

\section{REFERENCES}

1. Appleyard, M. M., The influence of knowledge accumulation on buyer-supplier codevelopment projects. Journal of Product Innovation Management, Vol. 20, No. 5, 2003, pp. 356-373.

2. Bapna, R., Barua, A., Mani, D., \& Mehra, A., Cooperation, coordination, and governance in multisourcing: An agenda for analytical and empirical research. Information Systems Research, 2010, 21(4), 785-795. https://doi.org/10.1287/isre.1100.0328.

3. Benbasat, I., A. S. Dexter, and R. W. Mantha, "Impact of Organizational Maturity on Information System Skill Needs," MIS Quarterly, Vol. 4, March 1980, pp. 21-34.

4. Bengtsson L, Von Haartman R, Dabhilkar M., "Low-cost versus innovation: contrasting outsourcing and integration strategies in manufacturing", Creativity and Innovation Management, Vol. 18, No. 1, 2009, pp. 35-47.

5. Bunmi Cynthia Adeleye, Fenio Annansingh, Miguel Baptista Nunes, (2004), "Risk management practices in IS outsourcing: an investigation into commercial banks in Nigeria", International Journal of Information Management, Vol. 24, No. 2, pp. 167-180

6. Cheon, M. J., "Outsourcing of Information Systems Functions: A Contingency Model," Doctoral Dissertation, College of Business Administration, University of South Carolina, 1992.

7. Cross, J., "IT Outsourcing: British Petroleum's Competitive Approach," Harvard Business Review, May-June 1995, pp. 94-102.

8. David A. Griffith, Nukhet Harmancioglu, Cornelia Droge, "Governance decisions for the offshore outsourcing of new product development in technology intensive markets Original Research Article", Journal of World Business, Vol. 44, No. 3, 2009, pp. 217-224

Gilley KM, Rasheed A., "Making more by doing less: an analysis of outsourcing and its effects on firm performance", Journal of Management, Vol. 26, No. 4, 2006, pp. 763-790.

9. Gregory, R., Prifling, M., \& Beck, R., The role of cultural intelligence for the emergence of negotiated culture in IT offshore outsourcing projects. Information Technology \& People, 2009, 22(3), 223-241. https://doi.org/10.1108/09593840910981428

10. Grover, V. and J. T. C. Teng, "The Decision to Outsource Information System Function," Journal of Systems Management, November 1993, pp. 84-97.

11. Grover, V., M. J. Cheon, and J. T. C. Teng, "A Descriptive Study on the Outsourcing of Information Systems Functions," Information Management, Vol. 27, 1994, pp. 33-44.

12. Handley SM, Benton WC, "Unlocking the business outsourcing process model" Journal of operations management, Vol. 27, No. 5, 2009, pp. 344-361.

13. Jennings $D$. "Strategic sourcing: benefits, problems and a contextual model", Manage Decision, Vol. 40, No.1, 2002, pp. 26-34.

14. Johnston, H. R. and S. R. Carrico, "Developing Capabilities to Use Information Strategically," MIS Quarterly, 1988, Vol. 12, No. 1, pp. 37-50.

15. Kang $\mathrm{M}$, Wu $\mathrm{X}$, Hong $\mathrm{P}$, and Park $\mathrm{Y}$, "Aligning organizational control practices with competitive outsourcing performance", Journal of Business Research, Vol. 65, 2012, pp.1195-1201

16. Karimi, J., Y. P. Gupta, and T. M. Somers, "Impact of Competitive Strategy and Information Technology Maturity on Firm's Strategic Response to Globalization," Journal of Management Information Systems, Vol. 12, No. 4, Spring 1996, pp. 55-88. 
17. Kudaravalli, S., Faraj, S., \& Johnson, S. L., A Configurational Approach to Coordinating Expertise in Software Development Teams. MIS Quarterly, 2017, 41(1), 43-64.

18. Lacity, M. C. and L. P. Willcocks, "An Empirical Investigation of Information Technology Sourcing Practices: Lessons from Experience," MIS Quarterly, Sep. 1998, pp. 363-408.

19. Lacity, M. C., L. P. Willcocks, and D. F. Feeny, "IT Outsourcing: Maximize Flexibility and Control," Harvard Business Review, May-June 1995, pp. 84-93.

20. Lacity, M., \& Willcocks, L., Conflict resolution in business services outsourcing relationships. Journal of Strategic Information Systems, 2017, 26(2), 80-100. https://doi.org/10.1016/j.jsis.2017.02.003

21. McFarlan, F. W., J. L. McKenney, and P. Pyburn, "The Information Archipelago-plotting a Course," Harvard Business Review, Jan. 1983.

22. Teng, J. T. C., M. J. Cheon, and V. Grover, "Decisions to Outsource Information Systems Functions: Testing a Strategy-Theoretic Discrepancy Model," Decision Sciences, 1995, Vol. 26, No. 1, pp. 75-103.

23. Wu B, Chen J, Wu Z., "The research of R\&D outsourcing mode, measurement and impact on firm innovative performance", Studies in Science of Science, Vol. 27, No. 2, 2009, pp. 302-308.

24. Zhou KZ, Li CB., "How strategic orientations influence the building of dynamic capability in emerging economies", Journal of Business Research, Vol. 63, No. 3, 2010, pp. 224231. 